\title{
DELIMITAÇÃO DOS PRINCÍPIOS BÁSICOS PARA A REALIZAÇÃO \\ DE PROPAGANDA ELEITORAL COM VISTAS AO APERFEIÇOAMENTO DA DEMOCRACIA.
}

\author{
DELIMITATION OF BASIC PRINCIPLES FOR THE REALIZATION \\ OF ELECTORAL PUBLICITY FOCUSED ON THE \\ OUR DEMOCRACY IMPROVING
}

\begin{abstract}
Marcos Antônio Striquer Soares
RESUMO: Analisa a dimensão constitucional da propaganda política eleitoral e os princípios básicos que devem ser observados em sua produção e veiculação. Constata a propaganda como uma técnica de comunicação persuasiva, cujo objeto é a divulgação de produtos, serviços ou idéias; para tanto, utiliza-se das artes e de algumas ciências para atingir seu intento. Não pode ser utilizada sem limites, já que pressupõe a persuasão, devendo respeitar a Constituição e as leis e, especificamente, os direitos individuais. Faz um paralelo entre a propaganda política eleitoral e a propaganda política partidária. Analisa os fundamentos do Direito Eleitoral na Constituição, para detectar pressupostos de veiculação de propaganda eleitoral. Verifica que os dispositivos fundantes do Direito Eleitoral, a partir dos quais esta área do Direito deverá ser estruturada, estão na Constituição. Os dispositivos constitucionais que dão sustentação ao Direito Eleitoral não estão ali apenas para incorporar uma Lei rígida. Eles apresentam um modo de ser do Estado, uma opção política formadora do perfil do Estado. Sem esse núcleo na Constituição não poderíamos falar em Democracia, em República, em soberania popular, pois aquele que viesse a exercer o poder teria possibilidade de controlar os mecanismos de acesso ao poder, controlando, também, os detentores dos cargos públicos e as funções fundamentais do Estado. Desse modo, a propaganda eleitoral, para ser veiculada, deve respeitar limitações previstas em lei. Esta, no entanto, deve respeitar regras e princípios previstos na Constituição. A especificação de princípios básicos para a veiculação de propaganda eleitoral possibilita a unidade do sistema jurídico eleitoral, já que ele passa a apresentar coerência entre pontos aparentemente conflitantes, e também serve para condicionar a atividade do intérprete, quando houver dúvidas quanto ao que é permitido e o que é proibido nessa área. São três os princípios constitucionais analisados: da igualdade, da liberdade e da legalidade. Encontrar o equilíbrio entre os princípios da liberdade e da igualdade deve ser objetivo da sociedade, no aperfeiçoamento de nossa prática democrática.
\end{abstract}

Palavras-chave: Propaganda eleitoral; Princípios constitucionais; Direito de voto; Direito Eleitoral; Democracia.

\footnotetext{
1 Marcos Antônio Striquer Soares é mestre e doutor em Direito do Estado/Direito Constitucional pela PUC/ SP; é professor de Direito Constitucional na graduação em Direito, na especialização em Direito do Estado e no mestrado em Direito Negocial, da UEL; é professor de Direito Constitucional na Universidade Norte do Paraná (UNOPAR) e na Universidade do Oeste Paulista (UNOESTE).
} 


\begin{abstract}
Analyzes the constitutional dimension of the electoral publicity and the basic principles to be followed in its production and dissemination. Sees the advertising as a technique of persuasive communication, where the object is the promotion of products, services or ideas. For that purpose, uses arts and some sciences to achieve their goal. It can not be used without limits, as it supposes persuasion, having to respect the Constitution, the laws and, specifically, individual rights. It establishes a parallel between electoral advertising and politics party advertising. Analyzes the Constitutional fundaments of the Electoral Law, to detect conditions for electoral publicity dissemination. Verifies that the founding devices of the Electoral Law, from which this area of law should be structured, are in the Constitution. The constitutional provisions that give support to the Electoral Law are not there just to incorporate a rigid law. They present a way of being of the State, a political option that forms the State profile. Without this core in the Constitution it would not be possible to talk about democracy, about Republic, about popular sovereignty, because the one who should come to exercise the power would be able to control the mechanisms of access to power, controlling also the holders of public office and the basic functions of the State. Thus, the canvass, to be disseminated, must comply with restrictions imposed by law. This, however, must comply with constitutional rules and principles. The specification of basic principles for electoral publicity dissemination, makes it possible the unit of the electoral legal system, as it begins to show consistency between seemingly conflicting points, and also serves to condition the activity of the interpreter, when there is doubt as to what is allowed and what is prohibited in this area. There are three constitutional principles analyzed: equality, freedom and legality. Finding the balance between the principle of freedom and the principle of the equality should be the goal of society in improving our democratic practice.
\end{abstract}

Palavras-chave: Electoral publicity; Constitutional principles, The right to vote, Electoral Law, Democracy.

\title{
INTRODUÇÃO
}

A disputa dos cargos públicos tem gerado grandes paradoxos para o direito e para a sociedade. Se se deixa a disputa livre aos concorrentes, o poder econômico pode sufocar pessoas menos abastadas e boas idéias destituídas de patrocínio financeiro; impondo-se limitação ao poder econômico, será difícil a um candidato levar suas idéias a um grande número de eleitores, proporcionando um debate político amplo, como se imagina para uma democracia. Por outro lado, as pessoas que já ocupam cargos públicos tendem a explorá-lo em benefício pessoal ou de seu grupo político; contudo, é inimaginável barrar a reeleição dos mandatários do povo ou impedir que o grupo dominante participe da disputa do poder. 
Aeleiçãotemsidoomecanismo deseleção dos representantes dopovo,nassociedadescontemporâneas, mas o processo eleitoral ainda deixa margem a muitos abusos. Apropaganda eleitoral, especificamente, é um campo onde a ordem é explorar todos os recursos que a técnica põe à disposição do publicitário, independentemente delegalidade. Paraagravar essa situação, as técnicas publicitárias são, hoje, muito desenvolvidas, exigindo atenção especial de quem pretende controlá-las.

O presente estudo busca as raízes da propaganda eleitoral na Constituição Federal para determinar as possibilidades de sua limitação, bem como de sua exploração. A sua dimensão constitucional deve ser o ponto de partida para a produção de leis, de decisões judiciais e decisões administrativas coerentes com o processo democrático, no âmbito do processo eleitoral. O direito ao voto é um direito fundamental assegurado no Título II da Constituição Federal, com status de cláusula pétrea, por previsão expressa. Contudo, o voto em si não é suficiente para assegurar legitimidade aos representantes do povo, é necessário que o voto ocorra em um ambiente democrático. A observância de princípios constitucionais na disputa eleitoral é passo significativo para a legitimidade do pleito e amadurecimento da democracia.

\section{A PROPAGANDA COMO GÊNERO}

A propaganda tem uma força enorme na sociedade de massas. É, atualmente, instrumento capaz de provocar grandes transformações na vida social. A origem dessa palavra encontramos em Rabaça e Barbosa (1998, p. 481):

[...] a palavra propaganda é gerúndio do lat. Propagare ('multiplicar', por reprodução
ou por geração, 'estender, propagar'), e foi introduzida nas línguas modernas pela
Igreja Católica, com a bula papal Congregatio de Propaganda Fide e com a funda-
ção da Congregação da Propaganda, pelo Papa Clemente VIII, em 1597. O conceito
de propaganda esteve essencialmente ligado a um sentido eclesiástico até o séc. 19,
quando adquiriu também significado político (continuando a designar o ato de disse-
minar ideologias, de incutir uma idéia, uma crença na mente alheia).

Voltando nossa atenção para o conceito de propaganda, encontramos elementos bastante apropriados em Rafael Sampaio (1997, p. 11), para quem propaganda pode ser entendida como "a manipulação planejada da comunicação visando, pela persuasão, promover comportamentos em benefício do anunciante que a utiliza”. Considerando o termo propaganda em sua origem, esta definição já não é tão selvagem, já não propõe implantar uma idéia ou uma crença na mente de alguém, embora aceite a idéia de persuasão. 
Para Ricardo Ramos (1998, p. 10 e 12), a propaganda propõe-se menos a vender e mais a criar um clima favorável ao anunciado, de simpatia e mesmo adesão. Prometer além disso, em seu nome, diz o autor, seria confundi-la com outras ações de natureza diversa, com a promoção de vendas, por exemplo. Segundo ele, "a propaganda é uma técnica de comunicação, a divulgar os benefícios de um produto, de um serviço ou de uma idéia, e que para sua expressão se vale das artes e de algumas ciências" (destaques nosso). A propaganda, porém, busca, sempre, algum tipo de benefício para o anunciante. Entendê-la como meio de divulgar os benefícios de algo pressupõe algum grau de persuasão, “o objetivo primordial da comunicação persuasiva é transmitir informações motivadoras, quer dizer, informações capazes de mobilizar as condutas e as crenças numa direção" (FERRÉS, 1998, p. 40).

Assim, podemos aceitar o significado de propaganda nos termos propostos por Ricardo Ramos, mas é preciso adensá-lo com elementos encontrados em Rafael Sampaio. Entendemos a propaganda como uma técnica de comunicação persuasiva, cujo objeto é a divulgação de produtos, serviços ou idéias; para tanto utiliza-se das artes e de algumas ciências para atingir seu intento .

A propaganda é, portanto, instrumento de comunicação social bastante rico em sua composição, utilizado para informar, simplesmente (mas, com a intenção determinada de fazer com que o destinatário assimile a informação transmitida - ela é persuasiva), ou, até mesmo, para induzir, para conduzir alguém à prática de um comportamento . Essa técnica de comunicação, de qualquer modo, não pode ser utilizada sem limites, já que pressupõe a persuasão, devendo respeitar a Constituição e as leis e, especificamente, os direitos individuais. Embora esse arsenal todo, reunido nesse instrumento denominado propaganda, não seja utilizado apenas para tornar algo público, também não pode ser tão perverso a ponto de conduzir os destinos de seu receptor.

\section{A PROPAGANDA POLÍICA ELEITORAL E POLÍCA PARTIDÁRIA}

A compreensão da propaganda eleitoral e da propaganda partidária deve iniciar com o exame da terminologia, pois ela ainda não é uniforme. Analisando a nossa legislação sobre o assunto, encontramos o Título II, da Parte Quinta do Código Eleitoral (Lei nº 4.737, de 15/07/1965) com a denominação “DA PROPAGANDA PARTIDÁRIA”. Contudo, o art. 240, esclarece que as normas ali fixadas são voltadas para a propaganda de candidatos a cargos eletivos. Por outro lado, a legislação mais recente faz diferenciação entre propaganda eleitoral e pro- 
paganda partidária. A lei 9.100, de 29/09/95 (hoje revogada), a qual regulamentou as eleições realizadas no ano seguinte a sua criação, trouxe um capítulo denominado "DA PROPAGANDA ELEITORAL", impondo limites à propaganda voltada para a conquista de cargos públicos. A lei em vigor que regulamenta as campanhas eleitorais com vistas à conquista de cargos públicos, via eleições populares, é a de nº.504, de 30/09/97, utiliza a expressão propaganda eleitoral em diversos capítulos.

A lei dos partidos políticos em vigor, lei n9.096, de 19/09/95, trata de outra espécie de propaganda política: a propaganda política partidária. Ela traz o Título IV com a denominação “DO ACESSO GRATUITO AO RÁDIO E À TELEVISÃO” e utiliza a expressão propaganda partidária em seus dispositivos para significar a divulgação de interesses dos partidos políticos e não de candidatos ou coligações.

Exercendo sua competência regulamentar (art. 23, IX do Código Eleitoral e art. 105 da lei 9.504/97), o Tribunal Superior Eleitoral baixou a Resolução n²3.191, de 16/12/2009 - a cada eleição baixa nova Resolução - dispondo sobre "a propaganda eleitoral e as condutas vedadas em campanha eleitoral (eleições de 2010)". Denomina "propaganda eleitoral", portanto, a propaganda realizada nas campanhas eleitorais para a conquista dos cargos públicos. Por outro lado, a Resolução do TSE n²0.304, de 27/11/97 trata da propaganda partidária, propaganda gratuita realizada pelos partidos políticos no rádio e na televisão fora do período eleitoral.

Não há conceito de propaganda eleitoral na Lei Eleitoral e tampouco na Resolução do TSE. A Lei 9.096/95 dos partidos políticos, no entanto, traz boas explicações sobre a propaganda partidária gratuita no rádio e na televisão, em seu art. 45 encontramos:

\footnotetext{
A propaganda partidária gratuita, gravada ou ao vivo, efetuada mediante transmissão por rádio e televisão será realizada entre as dezenove horas e trinta minutos e as vinte e duas horas para, com exclusividade: I - difundir os programas partidários; II - transmitir mensagens aos filiados sobre a execução do programa partidário, dos eventos com este relacionados e das atividades congressuais do partido; III - divulgar a posição do partido em relação a temas político-partidários.
}

Numa síntese de tais elementos, José Bispo Sobrinho (1996, p. 94) apresenta uma boa noção de propaganda partidária ou propaganda dos partidos políticos (comentando a propaganda gratuita no rádio e na televisão), realizada para: “difundir, com exclusividade, o seu programa, transmitir mensagens aos filiados sobre execução do programa, eventos e atividades congressuais da agremiação, bem como para divulgar a posição tomada sobre temas político-partidários". 
Analisando o conceito de propaganda eleitoral e propaganda partidária na doutrina, verifica-se uma diversidade de explicações: Pinto Ferreira (1998, p. 245), comentando o Código Eleitoral, no qual propaganda política tem o significado de propaganda eleitoral, afirma:

[...] a propaganda política é utilizada com o fim de favorecer a conquista dos cargos políticos pelos candidatos interessados, fortalecer-lhes a imagem perante o eleitorado, sedimentar a força do governo constituído, ou minar-lhe a base, segundo as perspectivas dos seus pontos de sustentação ou de contestação.

A noção de propaganda eleitoral apresentada (denominada pelo autor como propaganda política) confunde propaganda eleitoral com propaganda do próprio governo, pois o autor afirma que sua finalidade é "sedimentar a força do governo constituído". Isto, porém, é incoerente, não é possível confundir propaganda para a conquista ou manutenção de cargos públicos (ou para fazer oposição), com propaganda do governo. Conquanto os partidos governistas possam fazer propaganda de seu desempenho no governo, os órgãos públicos (o governo, propriamente), não podem fazer propaganda dos partidos governistas ou, em outras palavras, os partidos governistas não podem usar a máquina administrativa do Estado para promover os seus interesses.

Para Joel José Cândido (204, p. 149),

Propaganda Eleitoral ou Propaganda Política Eleitoral é uma forma de captação de votos usada pelos partidos políticos, coligações ou candidatos, em época determinada por lei, através da divulgação de suas propostas, visando à eleição a cargos eletivos. (...) Propaganda Política Partidária é a divulgação genérica e exclusiva do programa e da proposta política do partido, em época de eleição ou fora dela, sem menção a nomes de candidatos a cargos eletivos, exceto os partidários, visando a angariar adeptos.

Entendemos como propaganda política eleitoral a propaganda realizada por partido político, candidato ou coligação partidária em período eleitoral, para apresentar suas propostas de governo e apresentar pessoas capacitadas para desempenhar seus programas de governo, no intuito de conquistar os cargos públicos.

A propaganda partidária tem por objeto divulgar o programa e as propostas políticas do partido, não podendo promover pessoas ou facções internas do partido, embora deva apresentar seus membros ao povo, os responsáveis por seu programa e por suas propostas políticas. Ela pode ser realizada em qualquer época, em período eleitoral (estando proibido, aqui, a propaganda partidária gratuita no rádio e na televisão) ou fora dele. Por fim, quanto aos objetivos da 
propaganda partidária, estes correspondem aos objetivos legítimos do próprio partido político: conquistar o poder, manter o poder conquistado ou fazer oposição ao poder estabelecido.

No Brasil, a propaganda eleitoral tem disciplina rigorosa, havendo previsão legal específica para cada uma das diversas possibilidades de sua realização . A lei delimita, inclusive, o período em que é possível sua realização . Merece destaque a previsão de propaganda gratuita no rádio e na televisão (tanto para propaganda eleitoral como para propaganda partidária). Para evitar vantagens econômicas de um partido ou candidato, ou mesmo para evitar o trafego de influência que um partido ou candidato possa exercer sobre empresas de rádio e televisão, nossa legislação impõe a estas empresas de comunicação a veiculação gratuita de propaganda eleitoral (realizada no período eleitoral) e de propaganda partidária (só não havendo sua veiculação durante o período eleitoral, destinado à propaganda eleitoral gratuita). As emissoras terão direito à compensação fiscal pela cedência de horário gratuito (art. 99 da lei 9.504/97 e parágrafo único do art. 52 da lei 9.096/95).

Além disso, o art. 45 da lei 9.504/97 traz várias vedações para a veiculação da programação normal e noticiários das emissoras de rádio e televisão durante os meses de eleições. Tenta coibir, com isto, a propaganda velada, escondida em comentários, em entrevistas, em pesquisas de opinião favoráveis a um candidato. É proibido propaganda eleitoral ou partidária em troca de pagamento, ou mesmo em troca de favores, no rádio e na televisão. A intenção é preservar a igualdade entre aqueles que pretendem conquistar os cargos públicos, mantê-los ou fazer oposição ao grupo governista.

\section{PROPAGANDA ELEITORAL, PROPAGANDA PARTIDÁRIA, DIREITO ELEITO- RAL E MATÉRIA CONSTITUCIONAL: FUNDAMENTOS CONSTITUCIONAIS DO DIREITO ELEITORAL}

É necessário, a esta altura de nosso estudo, incluir o elemento jurídico nas propagandas eleitoral e partidária. São dois pontos fundamentais: em primeiro lugar, é preciso alocar as espécies de propaganda em nosso sistema jurídico. Em segundo lugar, verificar os princípios jurídicos que interferem na produção dessas propagandas.

As duas são regulamentadas por lei. O campo do conhecimento que tem como objeto de estudo essa legislação e sua aplicação é o Direito Eleitoral. A solução dos conflitos nesta seara é de competência de Justiça especial, a Justiça Eleitoral. Contudo, um grande número de matérias estudadas no Direito Eleitoral são matérias constantes da Constituição. 
Expõe Cármen Lúcia Antunes Rocha (1998, p. 30-31):

[...] a matéria eleitoral é, em grande parte, tida como constitucional. Mesmo quando tratada fora do texto constitucional, é certo que ela participa do texto constitucional, donde a sua quantidade de tema necessariamente presente no sistema constitucional. A forma de exercício da soberania popular e a organização dos poderes públicos, mormente o preenchimento dos cargos políticos por meio de eleição popular, guarda, nitidamente, natureza essencial [...] no sistema de Direito. A sua interpretação há de se fazer em perfeito ajuste aos princípios definidos no sistema constitucional e aos objetivos genéricos e específicos estabelecidos no ordenamento fundamental.

Em seguida a autora passa a indicar dispositivos da nossa Constituição que têm reflexo em todo o sistema jurídico eleitoral.

Em primeiro lugar ela cita o art. $1^{\circ}$ da Constituição Federal, apresentando-o como “núcleo básico estruturador do Estado.” Em seguida traz o art. 14, "forma de o cidadão fazer-se presente no processo político", contendo "as regras básicas sobre os direitos políticos, o que é a base para todas as normas relativas ao processo eleitoral, espaço próprio de exercício daqueles direitos." Faz referência, ainda, a todo o capítulo IV (Dos direitos políticos), do Titulo II (Dos direitos e garantias fundamentais), da Constituição e arremata:

\footnotetext{
A prática de regimes políticos democráticos ou a sua negação mostra-se no acatamento pleno de todas as normas jurídicas relativas ao processo político de participação do povo no exercício do poder, o que não está posto senão em seus grandes traços principiológicos e preceituais na Lei Fundamental, pois a pormenorização dos passos é definida na legislação infraconstitucional (ROCHA, 1998, p. 30-31).
}

Diversos dispositivos compõem esse núcleo de Direito Eleitoral contido na Constituição. Além daqueles já citados por Carmen Lúcia Antunes Rocha, ainda podemos fazer algumas considerações:

(a) - O art. 14, ao tratar da soberania popular, do sufrágio universal e do voto direito e secreto, com valor igual para todos, originado lá no parágrafo único do art. $1^{\circ}$ da Constituição - todo o poder emana do povo, que o exerce por meio de representantes eleitos ou diretamente define o titular do poder do Estado e o mecanismo de seleção de pessoas para seu exercício. Isto fica claro ao examinarmos os demais componentes desse art. 14, que estabelecem as condições para o alistamento eleitoral e para o voto e as condições de elegibilidade;

(b) - O $\S 9^{\circ}$, do art. 14, abre a possibilidade de controle rigoroso da normalidade e legitimidade das eleições contra a influência do poder econômico ou o abuso do exercício de 
função, cargo ou emprego na administração direta ou indireta, a fim de proteger a probidade administrativa, a moralidade para o exercício do mandato, considerada a vida pregressa do candidato. Aqui encontramos, de modo evidente, a preocupação contida na Lei, de manter a igualdade entre os concorrentes nas eleições. É princípio exigido no Direito Eleitoral em nível constitucional;

(c) - O art. 15 veda a cassação de direitos políticos, abrindo exceção a poucos casos de perda ou suspensão destes direitos;

(d) - O art. 16 determina que a lei que alterar o processo eleitoral entrará em vigor na data de sua publicação, não se aplicando à eleição que ocorra até 1 (um) ano da data de sua vigência;

(e) - Por fim, ainda podemos citar o art. $60, \S 4^{\circ}$, II, onde encontramos o voto direto, secreto, universal e periódico como dispositivo sobre o qual não se aceitará emenda tendente a aboli-lo. É cláusula pétrea. É cláusula que preserva na Constituição a essência do Direito Eleitoral, o voto, direito fundamental, possibilitando a participação do povo nas decisões do Estado, e fazendo essa opção de modo definitivo.

Esse conjunto de dispositivos não esgota a matéria constitucional eleitoral, certamente. Eles são citados aqui apenas para comprovar a raiz do Direito Eleitoral na Lei Maior.

Podemos dizer depois disso, que os dispositivos fundantes do Direito Eleitoral, a partir dos quais esta área do Direito deverá ser estruturada, estão na Constituição (assim como ocorre com o Direito Tributário e o Direito Administrativo). Os dispositivos constitucionais que dão sustentação ao Direito Eleitoral não se apresentam aleatoriamente, não estão ali apenas para incorporar uma Lei rígida. Eles apresentam um modo de ser do Estado, uma opção política formadora do perfil do Estado. Sem esse núcleo na Constituição não poderíamos falar em Democracia, em República, em soberania popular, pois aquele que viesse a exercer o poder teria possibilidade de controlar os mecanismos de acesso ao poder, controlando, também, os detentores dos cargos públicos e as funções fundamentais do Estado. Esse núcleo de dispositivos eleitorais contido na Constituição é matéria constitucional (tanto no aspecto material, para efeito de interpretação da Constituição, como formal), o qual exige desdobramentos, que vão ocorrer via legislação infra-constitucional. Esta legislação ainda carregará matéria constitucional. 


\section{PRINCÍPIOS BÁSICOS DA PROPAGANDA ELEITORAL: IGUALDADE, LIBERDA- DE E LEGALIDADE}

A propaganda política eleitoral, para ser veiculada, conforme já examinado, deve respeitar limitações previstas em lei. Esta, no entanto, deve respeitar princípios previstos na Constituição. A especificação de princípios básicos para a propaganda eleitoral possibilita a unidade do sistema jurídico eleitoral, já que ele passa a apresentar coerência entre pontos aparentemente conflitantes, e também serve para condicionar a atividade do intérprete, quando houver dúvidas quanto ao que é permitido e o que é proibido nessa área.

Os partidos políticos, candidatos, coligações e mesmo os cidadãos não podem fazer uso indiscriminado da propaganda eleitoral. Embora exista liberdade para informar a sociedade sobre o programa do partido, propostas de governo e qualidade de candidatos, a propaganda eleitoral sofre restrições impostas pela Constituição e pela legislação em geral, pois os partidos políticos têm em vista a conquista do poder, sua manutenção ou a influência no desempenho dele fazendo oposição. Assim, o princípio da liberdade de propaganda política sofre restrições advindas dos princípios da igualdade e da legalidade, que ganham especial destaque, haja vista o objetivo da propaganda (conquista dos cargos pelos quais o povo expressa sua vontade).

Diversos são os fundamentos para impor a igualdade entre os participantes do pleito. Apresentamos alguns: os candidatos têm por objetivo a conquista dos cargos pelos quais o povo expressa sua vontade; para a conquista desses cargos ocorre uma disputa e ela somente será justa se todos puderem concorrer com os mesmos instrumentos; o titular do poder do Estado é o povo e a lei deve evitar que ele seja ludibriado por propagandas enganosas; a lei deve preservar o princípio constitucional da liberdade do voto, pois o voto não pode ser induzido, por exemplo, por quem tenha mais dinheiro ou influência sobre os meios de comunicação - o poder econômico passou a ter, por provocar tamanha desigualdade, tratamento específico no processo eleitoral.

Como bem ensina Fávila Ribeiro (1993, p. 465),

\footnotetext{
A liberdade de propaganda mereceu compatível tratamento, como condição básica do processo eleitoral, garantindo a persistência de seguro esquema para funcionamento da competição democrática. As normas protetoras da liberdade aparecem em funcional implicação com os postulados de igualdade. Com a liberdade erguem-se as defesas dos eleitores, dos candidatos e dos partidos, impedindo os cerceamentos provindos das agências estatais. Por sua vez, com a igualdade, as defesas são mobilizadas para enfrentar as situações privilegiadas, as dominações sociais que possam de alguma maneira embaraçar e desnivelar o livre diálogo democrático.
} 
Em outra passagem o autor comenta a lei nº.091, de 15/08/74, denominada lei Etelvino Lins, que calafetou os principais flancos expostos ao assédio do poder econômico, anotando que ela limitou a propaganda eleitoral pelo rádio e televisão aos horários gratuitos; nos jornais impressos, admitiu somente a divulgação de curriculum vitae e o número correspondente do candidato; conferiu à Justiça a responsabilidade exclusiva pelo fornecimento de transporte e alimentação que se façam indispensáveis aos eleitores de áreas rurais; e acrescenta: "Deu-se uma limitação à liberdade de propaganda, desfrutada por uns poucos para elevação dos padrões democráticos na competição, com igualdade de todos os candidatos na comunicação com o eleitorado" (RIBEIRO, 1993, p. 476-478).

Percebemos, do texto citado, que liberdade e igualdade devem conviver em harmonia, especificamente ali com relação ao processo eleitoral. Os princípios não se excluem, ao contrário, se entrelaçam e se harmonizam, formando um todo homogêneo, capaz de dar sustentação ao direito invocado . No processo eleitoral não é diferente, havendo necessidade de conjugar a liberdade de propaganda com a igualdade entre todos que pretendem conquistar os cargos pelos quais o povo expressa sua vontade.

Quanto ao princípio da liberdade de propaganda, José Afonso da Silva (2000, p. 238) explica que ao Direito interessa cuidar apenas da liberdade objetiva. Neste sentido costuma-se falar em várias expressões externas da liberdade, dentre as quais é possível distinguir cinco grandes grupos: liberdade da pessoa física, de locomoção; liberdade de pensamento; liberdade de expressão coletiva; liberdade de ação profissional; liberdade de conteúdo econômico e social. Antes de todas estas possibilidades de expressão externa da liberdade, contudo, encontramos a liberdade de ação em geral, a liberdade geral de atuar, a qual se caracteriza como liberdadematriz, como liberdade-base para a expressão externa do ser humano. Esta liberdade de ação,

[...] decorre do art. $5^{\circ}$, II, da Constituição, segundo o qual ninguém será obrigado a fazer ou deixar de fazer alguma coisa senão em virtude de lei. [...] Vale dizer, o princípio é o de que todos têm a liberdade de fazer e de não fazer o que bem entender, salvo quando a lei determine em contrário. [...] esse dispositivo é um dos mais importantes do Direito Constitucional brasileiro, porque, além de conter a previsão da liberdade de ação (liberdade base das demais), confere fundamento jurídico às liberdades individuais e correlaciona liberdade e legalidade. Dela se extrai a idéia de que a liberdade, em qualquer de suas formas, só pode sofrer restrições por normas jurídicas preceptivas (que impõem uma conduta positiva) ou proibitivas (que impõem uma abstenção), provenientes do Poder Legislativo e elaboradas segundo o procedimento estabelecido na Constituição. Quer dizer: a liberdade só pode ser condicionada por um sistema de legalidade legítimo. 
Assim, então, a liberdade de propaganda eleitoral não pode ser entendida como liberdade de divulgar o que se queira, nos locais e por meios que cada um consiga acessar com o dinheiro ou a influência que possa ter. De modo algum.

Num primeiro instante, a liberdade de propaganda conhece as restrições advindas da própria Constituição (das regras e demais princípios constitucionais). Demonstrando que a Constituição possui o núcleo básico do Direito Eleitoral, elencando dispositivos a partir dos quais será criada toda a legislação eleitoral, aqui, o exemplo mais apropriado é o §9 $9^{\circ}$, do art. 14 , que abre a possibilidade de controle rigoroso da normalidade e legitimidade das eleições contra a influência do poder econômico ou o abuso do exercício de função, cargo ou emprego na administração direta ou indireta, a fim de proteger a probidade administrativa, a moralidade para o exercício do mandato, considerada a vida pregressa do candidato. Tal dispositivo, utilizado como exemplo, entre tantos outros, impõe sérias restrições à liberdade econômica e ao exercício de função, cargo ou emprego na administração direta ou indireta, possibilitando a igualdade na disputa dos cargos públicos, proibindo os excessos de quem tenha tais benefícios.

Dentro da própria Constituição ainda encontramos o princípio da legalidade. Ele serve, conforme visto, de sustentação à liberdade.

\footnotetext{
A sua significação é dúplice. De um lado representa o marco avançado do Estado de Direito, que procura jugular os comportamentos, quer individuais, quer dos órgãos estatais, às normas jurídicas das quais as leis são a suprema expressão. Nesse sentido, o princípio da legalidade é de transcendental importância para vincar as distinções entre o Estado constitucional e o absolutista [...]. Com o primado da lei cessa o privilégio da vontade caprichosa do detentor do poder em benefício da lei, que se presume ser a expressão da vontade coletiva. De outro lado, o princípio da legalidade garante o particular contra os possíveis desmandos do Executivo e do próprio Judiciário. Instaurase, em conseqüência, uma mecânica entre os Poderes do Estado, da qual resulta ser lícito apenas a um deles, qual seja o Legislativo, obrigar os particulares (BASTOS, 1997, p. 186).
}

O princípio da legalidade, portanto, apresentando-se como limite à atuação do Estado (e de quem possa exercer influência dentro dele) diante do cidadão, mas permite ao Estado, por meio de lei, delimitar um campo de atuação do cidadão além do qual ele não poderá ir. Assim, o princípio da legalidade é outro princípio básico da propaganda eleitoral.

Apesar do que já foi dito, entre os princípios constitucionais que oferecem limites à liberdade de propaganda o mais importante é sem dúvida o princípio da igualdade. 
É inegável que a propaganda é uma das formas de liberdade de expressão, de liberdade de pensamento, pelo que representa um direito a ser resguardado, mas, por outro lado, ergue-se também o direito dos cidadãos, dos eleitores no caso específico em tela, de serem protegidos contra métodos falsos de induzimento e persuasão, que possam levá-los à adoção de comportamentos distorcidos (GOMES, 1998, p. 174-175).

A isonomia impõe-se no sistema de direitos, diante das oportunidades que o Estado oferece, seja perante o gozo dos seus serviços, seja no uso dos seus bens, seja em relação ao poder de polícia, seja à vista de outras manifestações administrativas, ou de encargos que o Estado pode exigir aos cidadãos, como o poder de expropriar, de requisitar etc., seja relativamente às manifestações tributárias, disciplinares ou outras (ATALIBA, 1985, p. 134).

Chegamos, assim, à necessidade de igualar os participantes da competição. Celso Antônio Bandeira de Mello (1984, p.13-16) explica que o princípio da igualdade é voltado quer para o aplicador da lei quer para o próprio legislador. Significa que a lei não deve ser fonte de privilégios ou perseguições, mas instrumento regulador da vida social que necessita tratar eqüitativamente todos os cidadãos. Ao se cumprir uma lei, todos os abrangidos por ela hão de receber tratamento parificado, sendo certo, ainda, que ao próprio ditame legal é interdito deferir disciplinas diversas para situações equivalentes. O princípio da igualdade interdita tratamento desuniforme às pessoas. Sem embargo, sua função precípua reside exata e precisamente em dispensar tratamentos desiguais. Isto é, as normas legais nada mais fazem que discriminar situações, à moda que as pessoas compreendidas em umas ou em outras vêm a ser colhidas por regimes diferentes. Donde, a algumas são deferidos determinados direitos e obrigações que não assistem a outras, por abrigadas em diversa categoria regulada por diferente plexo de obrigações e direitos .

Com referência à atitude do Estado em face de desigualdades, Meirelles Teixeira (1991, p. 728-729) explica que a Ciência Política e a evolução do Direito trataram as desigualdades encaminhando uma de três atitudes: Desconhecendo essas desigualdades, fechando os olhos a essas diferenças de situações concretas apresentadas pela vida social, o Estado tratará igualmente a todos os indivíduos e a todas as situações - é a posição liberal-individualista; outra atitude do Estado é destruir as desigualdades, promovendo a igualdade de fato, a igualdade social absoluta, criando, por exemplo, a sociedade sem classes, sem desigualdades; a terceira atitude é procurar distinguir, entre as desigualdades sociais, duas categorias: desigualdades legítimas (as quais têm sua origem nos dotes naturais de talento, inteligência, aptidão, virtudes, esforço, von- 
tade retamente encaminhada) e desigualdades ilegítimas (as quais são desigualdades artificiais, criadas apenas pelos azares, desajustamentos ou injustiças da ordem social). De acordo com esta terceira orientação, nem o ordenamento jurídico, nem o Estado, fecharão os olhos, diante das desigualdades ilegítimas, nem tentarão reduzir a uma igualdade absoluta e impossível uma ordem social complexa, uma sociedade composta de homens desigualmente dotados, e desigualmente merecedores. É este o único sentido da verdadeira igualdade, da igualdade jurídica proporcional às situações sociais, e que rejeita tanto a igualdade jurídica meramente formal, quanto a igualdade social absoluta.

O princípio da igualdade é traduzido pela igualdade de oportunidades, igualdade material ou efetiva entre as pessoas. Contudo, essa igualdade só é válida, adequada, apropriada quando a lei eleitoral respeita as desigualdades legítimas e coíbe as manifestações advindas das desigualdades ilegítimas, quando a lei eleitoral evita o abuso por parte de alguns em detrimento de outros que se encontram na mesma condição (na disputa eleitoral). "A igualdade constitui medida da liberdade, como aplicação que é da justiça distributiva, que preside à distribuição racional e justa tanto dos benefícios, como dos deveres, encargos e restrições estatais" (TEIXEIRA, 1991, p. 739). Aquele que desejar ampliar a liberdade (de imprensa ou de propaganda, no processo eleitoral) deve pensar e explicar, antes, em que medida aceita e tolera a desigualdade entre os candidatos. As restrições impostas à propaganda eleitoral em virtude do princípio da igualdade têm seu lastro na própria Constituição, pois é um princípio jurídico, inscrito neste documento .

Karl Loewenstein (1970, p. 418-421) esclarece

[...]que la libertad política se encuentra en una encrucijada. Lo mismo que en el campo de la economía, el máximo de libertad política no es en absoluto idéntico con el grado óptimo de igualdad política. Si la tendencia actual continúa, se hará completamente inevitable un cierto control estatal sobre la economía de mercado libre de la opinión pública - semejante a las intervenciones estatales en la vida económica -, ya que, si no, la democracia constitucional llegará a un punto en el camino hacia su autodestrucción, en el que ya no habrá posibilidad de volverse atrás”.

Encontramos alguns textos que afirmam não ser possível estabelecer restrições à liberdade de propaganda eleitoral, em razão do art. 220 da Constituição (“a manifestação do pensamento, a criação, a expressão e a informação, sob qualquer forma, processo ou veículo não sofrerão qualquer restrição," observado o disposto na Constituição). Manuel Alceu Affonso Ferreira (1999, p. 342) diz causar espécie que ordenamentos de natureza eleitoral tragam 
vedações às emissoras de rádio e televisão para difundir opinião favorável ou contrária a candidatura, partido, coligação, a seus órgãos ou representantes (referindo-se ao art. 45, III, da lei 9.504/97). Elcias Ferreira da Costa (1998, p. 75-76) afirma que "a lei eleitoral anterior à Constituição vigente tem criado limitações ao exercício da propaganda política, revelando, neste ponto, mais do que o próprio constituinte, coerência com o princípio da supremacia do bem comum sobre interesses partidários e individuais". Analisando tais idéias, devemos alertar, antes de mais nada, que toda limitação à propaganda política, imposta pela legislação eleitoral ou partidária, deve ter seu fundamento na Constituição.

Conforme já examinado, o fundamento do Direito Eleitoral está na Constituição, onde encontramos um núcleo de disposições básicas para a formação desse ramo da Ciência do Direito. Além dos princípios da liberdade e da igualdade, conjugados em medida adequada às necessidades eleitorais e partidárias, podemos repetir, mais uma vez, o exemplo tirado do $\S 9^{\circ}$, do artigo 14, onde a Constituição impõe restrições à liberdade (já no âmbito do Direito Eleitoral), coibindo o poder econômico e o exercício de função, cargo ou emprego na administração direta ou indireta, em benefício da igualdade entre aqueles que intentam atingir o poder do Estado.

Em oposição àqueles que entendem não ser possível impor restrições aos meios de comunicação, encontramos o entendimento de Maria Garcia (2001, p. 104), para quem essa liberdade autorizada aos meios de comunicação não é ilimitada, pois a Constituição traz diversos dispositivos sobre a liberdade de expressão e comunicação social:

É que a liberdade demanda responsabilidade e a Constituição consagra essa dinâmica atribuindo a determinados veículos de comunicação social o seu efetivo papel na sociedade na qual se inserem e devem sua existência e da qual participam como agentes sociais, dentro dos princípios determinativos dessa atividade, conforme estabelecido no art. 221.

A liberdade de expressão, diz a autora, deve permanecer incólume, pois a ação é livre. Porém, os instrumento de comunicação social, rádio e televisão, podem sofrer restrições, pois previstas na própria Constituição.

Os meios de comunicação têm uma influência enorme sobre a sociedade; aceitá-la indistintamente é aceitar a dominação.

Devem os meios de comunicação ser tratados como Poder Social, como efetivamente o são, não podendo ser comparados com o homem no exercício de sua liberdade individual. Não há poder, como tal, que possa prescindir de controle, deixando ao vácuo o 
sistema de defesa dos interesses coletivos, pois é próprio de sua natureza expandir-se o quanto seja tolerado, e se o controle não for aplicado, na justa medida e com presteza, o clima de irresponsabilidade se instaura, testemunhando a inocuidade da ordem jurídica, corrompida pela complacência à impunidade (RIBEIRO, 1993, p. 48).

Suzana de Camargo Gomes (1998, p. 177) explica que:

[...] não se trata de censura prévia a coibir a propaganda que apresente um nítido conteúdo nocivo à sociedade, mas de um controle de molde a evitar, sempre que possível, os exageros e o cometimento de infrações eleitorais, sendo que os excessos praticados nessa área ensejarão responsabilidade, inclusive criminal, com apuração perante a Justiça Eleitoral.

Assim, o princípio da liberdade de propaganda deve ser conjugado com o princípio da igualdade, na disputa eleitoral para a conquista dos cargos pelos quais o povo manifesta sua vontade. Encontrar o equilíbrio entre ambos deve ser objetivo da sociedade, no aperfeiçoamento de nossa prática democrática. O princípio da legalidade, por seu turno, serve de escudo protetor do particular contra os abusos das autoridades públicas (inclusive contra aqueles que pretendem conquistar os cargos públicos na disputa eleitoral), servindo, também, como limite, e muitas vezes como dever, a ser observado por todos, evitando decisões estranhas ao interesse público.

Os princípios, quando confrontados entre si, não se excluem, integram-se harmoniosamente. Antes de ser um empecilho aos meios de comunicação, aos candidatos e cidadãos, deve ser o ponto de partida para obtermos resultados legítimos nos pleitos eleitorais.

\section{CONCLUSÃO}

Como espécie de propaganda, a propaganda eleitoral é técnica de comunicação persuasiva, realizada por partido político, candidato ou coligação partidária em período eleitoral, para apresentar suas propostas de governo e apresentar pessoas capacitadas para desempenhar seus programas de governo, no intuito de conquistar os cargos públicos. Essa intenção de conquistar cargos públicos tem seu núcleo fundamental da Constituição, a partir da qual a legislação eleitoral deve ser criada e interpretada, observando sempre os princípios a serem aplicados a essa área do conhecimento jurídico. 
Por outro lado, a propaganda eleitoral deve sofrer, como de fato sofre, controle do Estado, respeitando-se o princípio da legalidade, para assegurar o processo democrático. A liberdade de propaganda (que pode levar a abusos do poder econômico e dos cargos públicos) deve ser proporcionada de modo a permitir a igualdade entre os participantes do pleito. Cabe à lei delimitar a liberdade de propaganda para preservar a igualdade na disputa.

\section{REFERÊNCIAS}

ATALIBA, Geraldo. República e constituição. São Paulo: Revista dos Tribunais, 1985.

BASTOS, Celso Ribeiro. Curso de direito constitucional. 18. ed. São Paulo: Saraiva, 1997.

BISPO SOBRINHO, José. Comentários à lei orgânica dos partidos políticos. Brasília: Brasília Jurídica, 1996.

CÂNDIDO, Joel José. Direito eleitoral brasileiro. 11. ed. Bauru: EDIPRO, 2004.

CANOTILHO, José Joaquim Gomes. Direito constitucional. 6. ed. Coimbra: Almedina, 1993.

COSTA, Elcias Ferreira da. Direito eleitoral. 3. ed. Rio de Janeiro: Forense, 1998.

FERREIRA, Manuel Alceu Affonso. Imprensa e constituição. In: COLTRO, Antônio Carlos Mathias (Coord.). Constituição Federal de 1988: dez anos (1988-1998). São Paulo: Juarez de Oliveira, 1999. p.339-343.

FERREIRA, Pinto. Código eleitoral comentado. 5. ed. São Paulo: Saraiva, 1998.

FERRÉS, Joan. Televisão subliminar: socializando através de comunicações despercebidas. Tradução de Ernani Rosa e Beatriz A. Neves. Porto Alegre: Artmed, 1998.

GARCIA, Maria. Censura e comunicação social. Revista de Direito Constitucional e Internacional, São Paulo, n.34, p.99-104, jan./mar. 2001.

GOMES, Suzana de Camargo. A justiça eleitoral e sua competência. São Paulo: Revista dos Tribunais, 1998.

LAS CASAS, Alexandre Luzzi. Marketing: conceitos, exercícios, casos. 3. ed. São Paulo: Atlas, 1999.

LOEWENTEIN, Karl. Teoría de la constitución. 2. ed. Barcelona: Ediciones Ariel, 1970.

MELLO, Celso Antônio Bandeira de. Conteúdo jurídico do princípio da igualdade. 2. ed. São 
Paulo: Revista dos Tribunais, 1984.

RAMOS, Ricardo. Propaganda. 4. ed. São Paulo: Global, 1998. (Contato Imediato).

RIBEIRO, Fávila. Abuso de pode no direito eleitoral. 2. ed. Rio de Janeiro: Forense, 1993.

ROCHA, Cármen Lúcia Antunes. A Constituição segundo a lei eleitoral ou a lei eleitoral segundo a Constituição. Paraná Eleitoral, Curitiba : TER/PR, n.30 : 17-33, out./dez. 1998.

SAMPAIO, Rafael. Propaganda de A a Z: como usar a propaganda para construir marcas e empresas de sucesso. 5. ed. Rio de Janeiro: Campus, 1997.

SILVA, José Afonso da. Curso de direito constitucional positivo. 17. ed. São Paulo, Malheiros, 2000.

TEIXEIRA, José Horácio Meirelles. Curso de direito constitucional. Rio de Janeiro: Forense Universitária, 1991. 